\title{
Caffeine enhances upper body strength in resistance-trained women
}

\author{
Erica Goldstein*1, Patrick L Jacobs¹, Michael Whitehurst'1, Tina Penhollow¹ and Jose Antonio²
}

\begin{abstract}
Background: Research has indicated that low-to-moderate dosages of caffeine supplementation are ergogenic for sustained endurance efforts as well as high-intensity exercise. The effects of caffeine supplementation on strengthpower performance are equivocal, with some studies indicating a benefit and others demonstrating no change in performance. The majority of research that has examined the effects of caffeine supplementation on strength-power performance has been carried out in both trained and untrained men. Therefore, the purpose of this study was to determine the acute effects of caffeine supplementation on strength and muscular endurance in resistance-trained women.

Methods: In a randomized manner, 15 women consumed caffeine $(6 \mathrm{mg} / \mathrm{kg}$ ) or placebo (PL) seven days apart. Sixty min following supplementation, participants performed a one-repetition maximum (1RM) barbell bench press test and repetitions to failure at $60 \%$ of $1 \mathrm{RM}$. Heart rate (HR) and blood pressure (BP) were assessed at rest, 60 minutes postconsumption, and immediately following completion of repetitions to failure.

Results: Repeated measures ANOVA indicated a significantly greater bench press maximum with caffeine ( $p \leq 0.05)$ $(52.9 \pm 11.1 \mathrm{~kg}$ vs. $52.1 \pm 11.7 \mathrm{~kg})$ with no significant differences between conditions in $60 \% 1 \mathrm{RM}$ repetitions $(p=0.81)$. Systolic blood pressure was significantly greater post-exercise, with caffeine $(p<0.05)(116.8 \pm 5.3 \mathrm{mmHg}$ vs. $112.9 \pm$ $4.9 \mathrm{mmHg}$ ).

Conclusions: These findings indicate a moderate dose of caffeine may be sufficient for enhancing strength performance in resistance-trained women.
\end{abstract}

\section{Background}

Caffeine is naturally derived from ordinary food items such as tea leaves, cocoa, coffee beans, and chocolate $[1,2]$ and commonly consumed in the form of coffee, tea, and carbonated beverages[1,3]. Various physiological mechanisms associated with the ergogenic effects of caffeine have been described in the literature. It has been suggested that caffeine is an adenosine antagonist $[4,5]$ and the primary mode of action may be on the central nervous system [6]. Other studies have suggested that caffeine may also have the ability to alter substrate utilization by acting to increase fat oxidation and, thus, spare glycogen utilization $[7,8]$. In addition, studies have also indicated enhanced secretion of $\beta$-endorphins [9] during exercise with a subsequent decrease in pain perception

* Correspondence: erg1500@yahoo.com

1 Department of Exercise Science and Health Promotion, Florida Atlantic University, Boca Raton, FL 33431, USA

Full list of author information is available at the end of the article
[10], as well as an enhanced thermogenic response [11] and alteration of neuromuscular function and/or skeletal muscular contraction $[12,13]$.

The ergogenic properties of caffeine have been extensively studied and research has indicated that low-tomoderate $(\sim 3-6 \mathrm{mg} / \mathrm{kg})$ dosages of caffeine supplementation are ergogenic for sustained endurance efforts [7,1417] as well as high-intensity exercise [18-20]. The effects of caffeine supplementation on strength-power performance are equivocal, with some studies indicating a benefit $[18,21]$ and others demonstrating no significant change in performance [22,23]. In fact, a number of investigations have indicated that in trained males, a lowto-moderate dose of caffeine $(\sim 2-6 \mathrm{mg} / \mathrm{kg})$ was effective for significantly enhancing upper body strength performance $[18,21]$. However, other studies have suggested that with similar doses of caffeine no significant changes in upper body strength were apparent $[22,23]$. The difference in outcomes between these studies could be the 
result of a range of intensity within the separate protocols and levels of habituation to caffeine within subjects.

Investigations that have examined these same dynamics in women are scarce and vary in design and level of condition of the participants studied. Ahrens and colleagues reported results for two different investigations [24,25] that examined the effects of low-to-moderate $(3-6 \mathrm{mg} / \mathrm{kg})$ dosages of caffeine on moderate aerobic exercise in untrained women. In the first study [24] results indicated a significant increase in energy expenditure, but no effect on measures of heart rate (HR), respiratory exchange ratio, or rating of perceived exertion (RPE). Results of the second investigation [25] indicated no significant increase in performance for caffeine supplementation and muscular endurance. Finally, Anderson et al. [26] reported a significant improvement in time among trained oarswomen for a 2,000 $\mathrm{m}$ row, following what is considered to be a high dose of caffeine $(9 \mathrm{mg} / \mathrm{kg})$.

As suggested, the design and population of women studied in relation to caffeine supplementation is varied. In addition, there are no investigations in the available literature that report any outcomes related specifically to resistance-trained females. Therefore, the purpose of this study was to determine the acute effects of caffeine supplementation on strength and muscular endurance in resistance-trained women.

\section{Methods}

\section{Research Participants}

Fifteen resistance-trained females volunteered to serve as research participants for this investigation. Inclusion criteria stipulated that all subjects were between the ages of 18-45 and had participated in resistance training activities at least 3-5 days per week for the 6 month period immediately prior to enrollment in this study. Other inclusionary criteria included the ability to bench press $70 \%$ of individual body weight. All testing procedures were verbally explained in detail and subjects provided written informed consent prior to participation, in accordance with the guidelines established by the Institutional Review Board at a southeastern university.

\section{Study Protocol}

A double-blind, placebo-controlled, cross-over design was utilized in this investigation. Research participants were asked to attend three laboratory sessions. The first session was for familiarization, followed by two testing trials seven days apart using the same testing protocol. Either caffeine at a dose of $6 \mathrm{mg} / \mathrm{kg}$ or placebo (PL) was administered orally 60 minutes prior to testing, in randomized order (See Supplementation Protocol Section).

Research participants were directed to continue the same general lifestyle patterns of exercise and nutrition intake during each seven-day period prior to the two exercise testing sessions. To verify the consistency of diet, the subjects were directed to complete a 3-day dietary recall (two week days and one weekend day) for each week prior to testing. The dietary intake data were analyzed using ESHA Food Processor SQL dietary analysis software (ESHA Research, Salem, OR).

All research participants completed one familiarization session prior to participating in the two testing trials. During the familiarization session, the participants were instructed on proper technique and mechanics of the bench press exercise, according to the standard methods defined by Baechle and Earle [27] and the National Strength and Conditioning Association. Additionally, participants performed a series of lifts to determine their ability to bench press $70 \%$ of individual body weight.

On test days, participants were asked to report to the testing laboratory in the morning after a 12-hour period without food. Subjects were asked to refrain from participating in vigorous activity and to avoid the consumption of caffeinated food and beverages in the 24-hour period prior to testing.

\section{Supplementation Protocol}

The two exercise trials were performed under two conditions, one with caffeine and one without. The study supplementation consisted of $6 \mathrm{mg} / \mathrm{kg}$ of caffeine provided in powder form (Scivation/Primaforce, Graham, North Carolina), which was mixed with 16.9 ounces of commercially available flavored Propel ${ }^{\circ}$ Fitness Water. Each 16.9ounce serving of Propel $^{\circ}$ Fitness Water is 20 calories and five grams of carbohydrates. The placebo was the single 16.9-ounce serving of flavored Propel Fitness Water. The supplement assignments were blinded to both the research participants and the study investigators. Participants ingested the respective $6 \mathrm{mg} / \mathrm{kg}$ of caffeine or PL approximately 60 minutes prior to testing.

\section{Testing Protocol}

The assessment protocol consisted of testing to determine one repetition maximum (1RM) and repetitions to failure (RF) at $60 \%$ on a standardized barbell bench press. One-repetition maximum was determined in three to six sets with 2-minute rest intervals between sets [22]. Onerepetition maximum was estimated using data from the familiarization trial and the Mayhew regression equation. The participant completed a warm-up by performing 12 15 repetitions at $50 \%$ of anticipated maximum. The participant then performed five repetitions starting at $60 \%$ of anticipated 1RM. If the participant was successful lifting the weight five times, resistance was increased by $15 \%$ with three required lifts. The weight was then increased to $90 \%$ of estimated $1 \mathrm{RM}$, with one required lift. If the participant was successful, the weight was then increased to $100 \%$ of estimated $1 \mathrm{RM}$, or until the participant failed 
to complete a lift. The participant then rested for five minutes before completing the test for muscular endurance. The participant completed as many bench press repetitions as possible at $60 \% 1 \mathrm{RM}$ to assess muscular endurance [22].

Within five seconds of completing the final repetition, HR, blood pressure (BP), and RPE were recorded. Heart rate was measured using a Polar HR monitor system, and BP was recorded by manual sphygmomanometry. All measurements were performed by the same technician. Total weight lifted was determined as repetitions $x$ weight.

\section{Statistics}

All outcome measures were statistically examined to determine whether there were significant differences between conditions (Caffeine, PL) using one-way ANOVA procedures with repeated measures. In all cases, a p-value of less than 0.05 was accepted to determine statistical significance. All data analyses were performed using SPSS, Version 16.

\section{Results}

Fifteen resistance-trained women completed both exercise trials. The study participants were aged $24.6 \pm 6.9$ years with a mean body mass of $63.6 \pm 8.3 \mathrm{~kg}$ and stature of $166.2 \pm 9.0 \mathrm{~cm}$. The 15 study participants were confirmed to satisfy the inclusion criteria, and demonstrated the ability to perform bench press repetitions to failure at a resistance that was equivalent to $70 \%$ of individual body weight.

\section{Dietary log data}

Macronutrient intake values for both study conditions are presented in Table 1. Dietary intake data for protein (g), carbohydrates (g), and fats (g) as well as total calories were analyzed to determine daily averages, which were compared between study conditions. Analysis indicated that there were no significant differences in these nutrient values for the three-day periods preceding each of the two exercise trials.

\section{Strength and Muscular Endurance}

Analysis indicated a significantly greater bench press maximum with caffeine $(\mathrm{p}<0.05)(52.9 \pm 11.1 \mathrm{~kg}$ vs. 52.1 $\pm 11.7 \mathrm{~kg})$. No significant differences were observed between conditions for 60\% 1RM repetitions ( $\mathrm{p}=0.81$ ) (Table 2). Caffeine consumption within subjects ranged from $0-416 \mathrm{mg}$ per day. Eight subjects consumed $\leq 250$ $\mathrm{mg}$ per day and seven consumed $\geq 250 \mathrm{mg}$ per day.

\section{Heart Rate and Blood Pressure}

Heart rate and BP were recorded at rest, $60 \mathrm{~min}$ following ingestion of the supplement (Caffeine, PL), as well as immediately post-exercise (see Table 3 ). No differences were observed for HR at any of the three time points. There was no difference between conditions for diastolic blood pressure (DBP) either at rest, 60 min post-consumption, or immediately following exercise. There were no differences between conditions for systolic blood pressure (SBP) either at rest or 60 min following supplementation; however, SBP was significantly greater immediately following exercise with caffeine $(\mathrm{p}<0.05)$ $(116.8 \pm 5.3 \mathrm{mmHg}$ vs. $112.9 \pm 4.9 \mathrm{mmHg})$.

\section{Discussion}

The major finding of this study is that acute caffeine supplementation appears to be effective for enhancing strength performance in resistance-trained women, as demonstrated by a significant increase in bench press 1RM. Caffeine supplementation at $6 \mathrm{mg} / \mathrm{kg}$ had no statistically significant effect on muscular endurance, HR, or DBP. Caffeine consumption did result in a $4 \mathrm{mmHg}$ increase in SBP immediately following exercise testing, which included determination of $1 \mathrm{RM}$, a 5-min rest inter$\mathrm{val}$, and RF at $60 \%$ of individual $1 \mathrm{RM}$.

These results are in disagreement with Astorino et al. [22], as the authors of that investigation reported no significant increase in upper body strength in resistancetrained males after consuming $6 \mathrm{mg} / \mathrm{kg}$ of caffeine. However, the outcomes of research investigations that have examined the effects of low-to-moderate dosages of caffeine on strength-power performance have been somewhat inconsistent. Accordingly, no other studies have specifically examined the effects of caffeine supplementation on strength or muscular endurance in resistancetrained women. Recently, Woolf et al. [18] demonstrated that a moderate dose of caffeine $(5 \mathrm{mg} / \mathrm{kg})$ was effective for enhancing performance for the chest press and peak power on the Wingate. Participants in that study [18]

Table 1: Nutrient consumption three days prior to each experimental protocol (means \pm SD).

\begin{tabular}{lcc}
\hline & Placebo & Caffeine \\
\hline Total energy (kcal) & $2160 \pm 1008$ & $2083 \pm 1095$ \\
Protein (g) & $103 \pm 46$ & $102 \pm 39$ \\
Carbohydrate (g) & $252 \pm 144$ & $256 \pm 186$ \\
Fat (g) & $145 \pm 274$ & $117 \pm 181$ \\
\hline
\end{tabular}


Table 2: Muscle strength and endurance data (means \pm SD).

\begin{tabular}{ccc}
\hline & Placebo & Caffeine \\
\hline Bench Press & & \\
1RM $(\mathrm{kg})$ & $52.1 \pm 11.7$ & $52.9 \pm 11.1^{*}$ \\
$60 \% 1 \mathrm{RM}$ & $23.0 \pm 7.1$ & $23.1 \pm 6.2$ \\
\hline * & & \\
\hline
\end{tabular}

* Indicates significant difference between conditions, $p<0.05$.

were conditioned male athletes, and the results are similar to those of Beck and colleagues [21], who reported a significant increase in upper body strength following a low dose $(2.1-3.0 \mathrm{mg} / \mathrm{kg})$ of caffeine in resistance-trained males.

In contrast, a different group of authors found no increase in strength, for either the bench press or front latissimus dorsi pull down, following ingestion of either caffeine at an absolute dose of $300 \mathrm{mg}$, or the combination of caffeine plus ephedra $(60 \mathrm{mg})$ [28]. In addition, a different study published by Beck et al. [29] reported no change in performance for untrained males, who received the same dose of caffeine $60 \mathrm{~min}$ prior to performing a $1 \mathrm{RM}$ test on the bench press. More recently, Woolf et al. [23] demonstrated that in non-habituated trained male athletes, caffeine supplementation $(5 \mathrm{mg} / \mathrm{kg})$ had no significant affect on bench press performance.

The dosage selected for the present study was based in part on the findings of Ahrens et al. [24]. In that study a moderate dose of caffeine $(6 \mathrm{mg} / \mathrm{kg})$ was effective for enhancing a metabolic response in untrained women. Ahrens et al. [24] also reported symptoms related to a high caffeine dose of $9 \mathrm{mg} / \mathrm{kg}$. Women reported feelings of profuse sweating, body tremors, dizziness, and vomit- ing. The subjects in the present investigation reported a wide range in caffeine habituation as indicated by reported daily intake ranging from zero to $416 \mathrm{mg}$ per day. Three of the 15 participants, who consumed either 0$41 \mathrm{mg}$ per day, exhibited intense emotional responses, including an expressed inability to verbally communicate, focus, and/or remain still, as well as the feeling of wanting to cry. In addition, two of the three participants, who experienced an intense emotional response, demonstrated an improvement in performance during the muscular endurance portion of the protocol. In other words, these participants performed more repetitions to failure at $60 \%$ of individual $1 \mathrm{RM}$.

Astorino et al. [22] reported symptoms that included restlessness, tremor, greater energy, and elevated HR. In addition, these feelings were augmented in those participants who consumed little caffeine on a daily basis. It is possible that caffeine consumption for some individuals will result in an enhancement in performance, second to feelings that present a loss of focus or emotional unrest. However, in other individuals the result may be in an increase performance without any presentable symptoms.

Table 3: Cardiovascular Response data (means \pm SD).

\begin{tabular}{|c|c|c|}
\hline & Placebo & Caffeine \\
\hline \multicolumn{3}{|l|}{ Heart rate (bpm) } \\
\hline Rest & $68.3 \pm 10.3$ & $68.5 \pm 13.3$ \\
\hline 60-min post supplementation & $67.3 \pm 10.2$ & $70.0 \pm 10.4$ \\
\hline Immediately post exercise & $90.0 \pm 14.0$ & $94.0 \pm 16.0$ \\
\hline \multicolumn{3}{|l|}{ Diastolic blood pressure $(\mathrm{mmHg})$} \\
\hline Rest & $63.3 \pm 5.0$ & $65.0 \pm 6.5$ \\
\hline 60-min post supplementation & $63.0 \pm 4.4$ & $64.4 \pm 5.3$ \\
\hline Immediately post exercise & $63.0 \pm 4.5$ & $64.3 \pm 5.2$ \\
\hline \multicolumn{3}{|l|}{ Systolic blood pressure (mmHg) } \\
\hline Rest & $109.4 \pm 5.5$ & $110.3 \pm 5.2$ \\
\hline $60-$ min post supplementation & $111.6 \pm 6.8$ & $111.0 \pm 5.6$ \\
\hline Immediately post exercise & $112.9 \pm 4.9$ & $116.8 \pm 5.3^{*}$ \\
\hline
\end{tabular}

* Indicates significant difference between conditions, $p<0.05$. 
Therefore, the difference in outcomes between investigations that have examined the effect of caffeine supplementation and strength-power performance could be the result of a variation of intensity within the separate protocols, a difference in relative dosages of caffeine, and wide ranging levels of caffeine habituation. Participants in the Beck et al. [21] study consumed a low dose of caffeine and performed repetitions to failure at $80 \%$ of individual 1RM on the bench press. In contrast, the study design for the Astorino et al. [22] publication included repetitions to failure at $60 \%$ of individual 1RM on the bench press and a caffeine dosage of $6 \mathrm{mg} / \mathrm{kg}$.

It is also possible that a magnitude of effect may exist, and it is greater for those individuals non-habituated to caffeine. Bell et al. [30] reported a positive effect on performance for participants classified as users $(\geq 300 \mathrm{mg} / \mathrm{d}$ ) and nonusers ( $\leq 50 \mathrm{mg} / \mathrm{d}$ ) of caffeine. Individuals identified as nonusers exhibited a treatment effect at $6 \mathrm{hrs}$ post consumption, which was not the case for users - this group only had a significant increase in endurance performance at 1 and 3 hours post consumption [30].

Other investigations have reported dissimilarity in performance between male and female athletes. Bruce et al. [20] used both a 6 and $9 \mathrm{mg} / \mathrm{kg}$ dose of caffeine when testing competitive oarsmen and women. In men [20], both dosages of caffeine were effective for enhancing time trial completion and average power output; however, the $9 \mathrm{mg} / \mathrm{kg}$ dose did not result in any further additional increases in performance. Results for the women [26] had an opposite effect: in a 2,000-m row, only the higher dose $(9 \mathrm{mg} / \mathrm{kg})$ resulted in a significant improvement in time. It is possible that a difference in response to caffeine supplementation exists between male and female athletes.

A second investigation published by Astorino et al. [31] examined cardiovascular responses to caffeine supplementation and resistance exercise in men. Systolic blood pressure was approximately 8-10 $\mathrm{mmHg}$ higher following caffeine ingestion and resistance exercise, as compared with placebo [31]. These results are comparable to the present investigation, where a significant increase in SBP occurred, but to a lesser extent of $4 \mathrm{mmHg}$.

Results published by Hartley et al. [32] also indicated an approximate $4 \mathrm{mmHg}$ increase in BP following caffeine supplementation $(3.3 \mathrm{mg} / \mathrm{kg})$, but for both male and female subjects. Participants in the Hartley et al. [32] investigation did not perform exercise but instead performed mentally stressful tasks such as public speaking and reading aloud. The suggested mechanisms responsible for the increase in BP were different. Specifically, women responded to caffeine with an increase in cardiac output facilitated by an increase in stroke volume. Men, however, had no change in cardiac output but instead responded with an increase in peripheral resistance.

\section{Conclusion}

In conclusion, the major finding of this study is that a 6 $\mathrm{mg} / \mathrm{kg}$ dose of caffeine was effective for enhancing strength but not muscular endurance in resistancetrained women. This is a novel finding as it is the first investigation to examine caffeine supplementation among this population. These results are specific to trained women, and should not be generalized to both male and female athletes. It is also apparent that a limitation to this study is the small sample size. Recruiting resistance-trained women, specifically those with the ability to bench press $70 \%$ of individual body weight, was difficult. Specifically many recreationally trained women, who frequently participate in resistance training, underestimate the conditioning that is essential for a female to bench press a relatively high percentage of body weight. While inclusionary criteria of this study limited subjects to females, who possessed an acceptable level of upper body strength, it is recommended that future investigations examine the effects of a $6 \mathrm{mg} / \mathrm{kg}$ dose of caffeine on lower body strength and muscular endurance in resistance trained women.

In addition, it is also recommended that future investigations examine whether a lower dose of caffeine would stimulate a similar increase in strength performance, as indicated by results of this study, but without the intense emotional response that was experienced by some of the participants. Overall, results of this study indicate a moderate dose of caffeine prior to resistance-exercise may be beneficial for increasing upper body strength performance in resistance-trained women.

\section{Competing interests}

The authors declare that they have no competing interests.

\section{Authors' contributions}

All authors contributed to the study design and reviewed and contributed to the final manuscript. EG and PJ were responsible for data collection, statistical analysis, and manuscript preparation. All authors have read and approved the final manuscript.

\section{Acknowledgements}

The authors wish to express sincere thanks to the individuals who participated or assisted in the project, for dedicating their time and effort as a contribution to this research study. In addition, we would like to thank Patricia Graham for her time and commitment; she was an incredible asset to this study.

\section{Author Details}

1Department of Exercise Science and Health Promotion, Florida Atlantic University, Boca Raton, FL 33431, USA and 2Nova Southeastern University, Fort Lauderdale-Davie, FL 33314, USA

Received: 19 March 2010 Accepted: 14 May 2010

Published: 14 May 2010

\section{References}

1. McArdle WD, Katch Fl, Katch VL: Sports \& exercise nutrition. Baltimore (MD): Lippincott Williams \& Wilkins; 2005. (Series Editor)

2. Powers SK, Howley ET: Exercise physiology: Theory and application to fitness and performance. New York: McGraw-Hill; 2004. (Series Editor)

3. Harland B: Caffeine and nutrition. Nutrition 2000, 16:522-526. 
4. Fredholm BB, Battig K, Holmen J, Nehlig A, Zvartau EE: Actions of caffeine in the brain with special reference to factors that contribute to its widespread use. Pharmacol Rev 1999, 51:83-133.

5. Spriet LL, Gibala MJ: Nutritional strategies to influence adaptations to training. J Sports Sci 2004, 22:127-41.

6. Spriet LL: Caffeine and performance. Int J of Sport Nutr 1995, 5:S84-99.

7. Ivy JL, Costill DL, Fink WJ, Lower RW: Influence of caffeine and carbohydrate feedings on endurance performance. Med SciSports Exerc 1979, 11:6-11

8. Essig D, Costill DL, Van Handel PJ: Effects of caffeine ingestion on utilisation of muscle glycogen and lipid during leg ergometer exercise. Int J of Sports Med 1980, 1:86-90.

9. Laurent D, Schneider KE, Prusaczyk WK, Franklin C, Vogel SM, Krssak M, Petersen KF, Goforth HW, Shulman Gl: Effects of caffeine on muscle glycogen utilization and the neuroendocrine axis during exercise. $J$ Clin Endocrinol Metab 2000, 85:2170-75.

10. Grossman A, Sutton JR: Endorphins: What are they? How are they measured? What is their role in exercise? Med Sci Sports Exerc 1985, 17:74-81.

11. Astrup A, Toubro S, Cannon S, et al:: Caffeine: A double-blind, placebocontrolled study of its thermogenic, metabolic, and cardiovascular effects in healthy volunteers. Am J Clin Nutr 1990, 51:759-67.

12. Kalmar JM, Cafarelli E: Effects of caffeine on neuromuscular function. $J$ Appl Physiol 1999, 87:801-808.

13. Lopes JM, Aubier M, Jardim J, Aranda JV, Macklem PT: Effect of caffeine on skeletal muscle function before and after fatigue. J Appl Physiol: Respirat Environ Exercise Physiol 1983, 54:1303-1305.

14. Hogervorst E, Bandelow S, Schmitt J, Jentjens R, Oliveira M, Allgrove J, Carter T, Gleeson M: Caffeine improves physical and cognitive performance during exhaustive exercise. Med Sci Sports Exerc 2008, 40:1841-51.

15. Graham TE, Hibbert E, Sathasivam P: Metabolic and exercise endurance effects of coffee and caffeine ingestion. J Appl Physiol 1998, 85:883-889.

16. McLellan TM, Bell DG: The impact of prior coffee consumption on the subsequent ergogenic effect of anydrous caffeine. Int J of Sport Nutr Exerc Meta 2004, 14:698-708.

17. Pasman WJ, van Baak MA, Jeukendrup AE, de Haan A: The effect of different dosages of caffeine on endurance performance time. Int $J$ of Sports Med 1995, 16:225-30.

18. Woolf K, Bidwell WK, Carlson AG: The effect of caffeine as an ergogenic aid in anaerobic exercise. Int J of Sport Nutr Exerc Meta 2008, 18:412-29.

19. Glaister M, Howatson G, Abraham CS, Lockey RA, Goodwin JE, Foley P, McInnes $G$ : Caffeine supplementation and multiple sprint running performance. Med Sci Sports Exerc 2008, 40:1835-40.

20. Bruce CR, Anderson ME, Fraser SF, Stepto NK, Klein R, Hopkins WG, Hawley JA: Enhancement of 2000-m rowing performance after caffeine ingestion. Med Sci Sports Exerc 2000, 32:1958-1963.

21. Beck TW, Housh TJ, Schmidt RJ, Johnson GO, Housh DJ, Coburn JW, Malek $\mathrm{MH}$ : The acute effects of a caffeine-containing supplement on strength, muscular endurance, and anaerobic capabilities. J Strength Cond Res 2006, 20:506-510.

22. Astorino TA, Rohmann RL, Firth K, Kelly S: Effect of caffeine ingestion on one-repetition maximum muscular strength. European Journal of Applied Physiology 2008, 102:127-132.

23. Woolf $\mathrm{K}$, Bidwell WK, Carlson AG: Effect of caffeine as an ergogenic aid during anaerobic exercise performance in caffeine naive collegiate football players. J Strength Cond Res 2009, 23:1363-1369.

24. Ahrens JN, Crixell SH, Lloyd LK, Walker JL: The physiological effects of caffeine in women during treadmill walking. Journal of strength conditioning research 2007, 21:164-68.

25. Ahrens JN, Lloyd LK, Crixell SH, Walker JL: The effects of caffeine in women during aerobic-dance bench stepping. Int J of Sport Nutr Exerc Meta 2007, 17:27-34.

26. Anderson ME, Bruce CR, Fraser SF, Stepto NK, Klein R, Hopkins WG, Hawley JA: Improved 2000-meter rowing performance in competitive oarswomen after caffeine ingestion. Int J of Sport Nutr Exerc Meta 2000, 10:464-75.

27. Baechle TR, Earle RW: Essentials of strength training and conditioning. Champaign: Human Kinetics; 2000. (Series Editor)

28. Williams AD, Cribb PJ, Cooke MB, Hayes A: The effect of ephedra and caffeine on maximal strength and power in resistance-trained athletes. J Strength Cond Res 2008, 22:464-70.
29. Beck TW, Housh TJ, Malek MH, Mielke M, Hendrix R: The acute effects of a caffeine-containing supplement on bench press strength and time to running exhaustion. J Strength Cond Res 2008, 22:1654-8.

30. Bell DG, McLellan TM: Exercise endurance 1, 3, and $6 \mathrm{~h}$ after caffeine ingestion in caffeine users and nonusers. J Appl Physiol 2002, 93:1227-1234

31. Astorino TA, Rohmann RL, Firth K, Kelly S: Caffeine-induced changes in cardiovascular function during resistance training. Int $\mathrm{J}$ of Sport Nutr Exerc Meta 2007, 17:468-477.

32. Hartley TR, Lovallo WR, Whitsett TL: Cardiovascular effects of caffeine in men and women. Am J Cardiol 2004, 93:1022-1026.

doi: 10.1186/1550-2783-7-18

Cite this article as: Goldstein et al., Caffeine enhances upper body strength in resistance-trained women Journal of the International Society of Sports Nutrition 2010, 7:18

\section{Submit your next manuscript to BioMed Central and take full advantage of:}

- Convenient online submission

- Thorough peer review

- No space constraints or color figure charges

- Immediate publication on acceptance

- Inclusion in PubMed, CAS, Scopus and Google Scholar

- Research which is freely available for redistribution

Submit your manuscript at www.biomedcentral.com/submit
C) Biomed Central 